\section{CHAIR WITH FLEXIBLE SPECIFICATION}

Takara Belmont has recently launched the Cleo II treatment centre which combines good looks with functionality. The Cleo already boasts a folding leg rest making it as easy as sitting in an armchair. This makes it less intimidating for patients, whilst

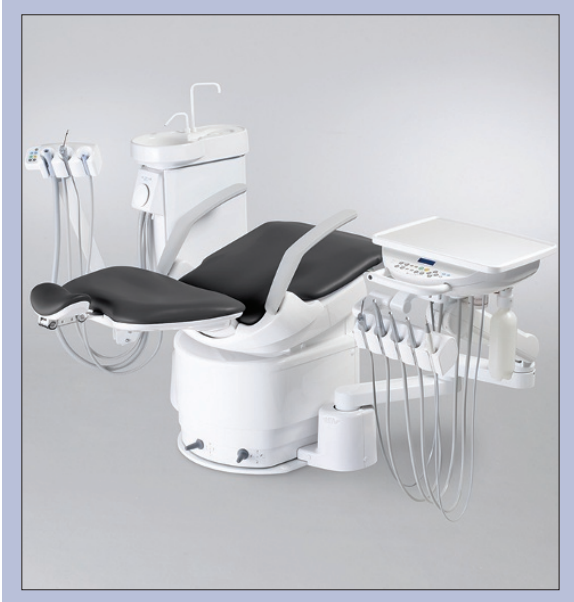

offering obvious ergonomic benefits to the operator.

Its small footprint and flexible specification opens up many surgery planning options and ensures that one really can suit all. The Cleo II is available in either air or electric options, the latter of which offers fibre optics, micro-motor, endodontic features and digitial displays as standard.

Cleo II's foldaway armrest now rotates $180^{\circ}$ thus facilitating patient access, particularly beneficial for disabled or elderly patients. Similarly, the $90^{\circ}$ cuspidor swivel action also adds to the ingenious ergonomics, logically easing both DSA and operator access. The system can also incorporate the outstanding NDL dental light with composite safe mode and third axis light head rotation.

Reader response number 62

\title{
MICRO-TECHNOLOGY FOR VISUAL CLARITY
}

Everclear from Nuview is a dental mirror that self-cleans. The Swiss design uses the latest precision micro-technology to create a tool dentists can trust to provide constant visual clarity.

Everclear uses a high optical-polish mirror that spins away spray and debris to provide continuous visibility. Powered by a quiet motor, its micromagnets allow an instant change of the doublesided mirrors, which float on aerospace ceramic ball bearings.

Visual acuity is increased and time is saved with no repetitive cleaning. Everclear is also ergonomically balanced with a cordless, non-slip medical stainless steel handle, has long-lasting,

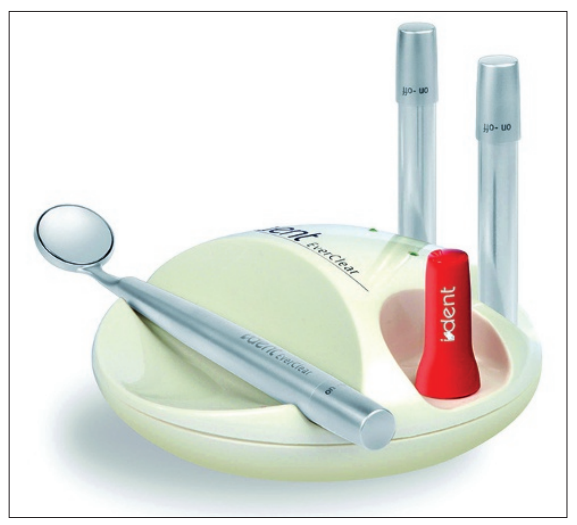

rechargeable batteries, with an extra battery on charge ensuring continuous performance, and is fully autoclavable. Reader response number 63

\section{COMPRESSORS WITH LOW NOISE LEVELS}

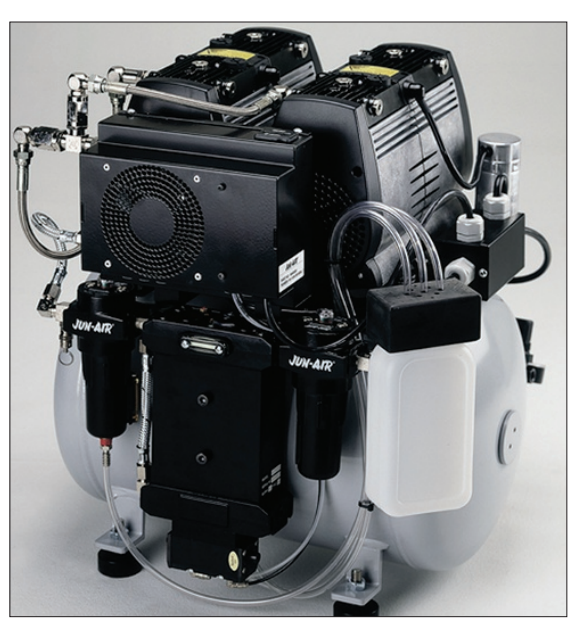

Jun-Air, supplier of compressed air to the dental market, has developed special packages for different sizes and types of practice, ranging from single to multiple surgeries for refurbished and new-build installations.

To meet the growing demand for clean, bacteria-free compressed air in dental surgeries, it produces a range of air compressors that comply with HTM 2022 and offers a combination of low noise levels, reliability, long life and low maintenance.

The oil-less compressors are ideally suited for use in single and multiple surgeries, and when housed in smart, soundproof cabinets, they also reduce noise levels.

Jun-Air packages - based on the company's OF300, 2000 and 4000 Series models - come complete with compressors, receivers, filters and adsorption dryers to ensure that the compressed air in contact with instruments, patients and staff is $100 \%$ dry, clean and bacteria-free. They can also be supplied as stand-alone units or as fully assembled cabinet solutions. Reader response number 64

\section{HARNESS TEXTING TECHNOLOGY}

Missed appointments are an all too familiar problem for both private and NHS dental practices. Software of Excellence have recognised that with 51 million mobile phone users in the UK, the introduction of a text alert system is a fast, immediate and effective way of reminding patients about appointments by simply sending a text message.

The technology allows you to automatically send a text reminder to your patients up to three hours before their appointment, and then shows the delivery status of messages in your Exact appointment book. Default messages can also be set up for appointment recalls and missed appointments, helping to reduce 'failed to attends' by up to $50 \%$ and increasing successful patient recall.

With the cost of sending a text being less than a third of the cost of postage, there are significant financial and efficiency savings to be made, meaning your practice can benefit from increased profitability through having a lower number of missed appointments.

Reader response number 65 